International Review of Research in Open and Distributed Learning Volume 21, Number 1

January - 2020

\title{
The Relationships Between Self-Efficacy, Task Value, and Self-Regulated Learning Strategies in Massive Open Online Courses
}

Daeyeoul Lee, Sunnie Lee Watson, and William R. Watson

Purdue University

\begin{abstract}
This study examines the relationships between self-efficacy, task value, and the use of self-regulated learning strategies by massive open online course (MOOC) learners from a social cognitive perspective. A total of 184 participants who enrolled in two MOOCs completed surveys. The results of Pearson's correlation analysis show a positive correlation between self-efficacy and the use of self-regulated learning strategies, as well as a positive correlation between task value and the use of self-regulated learning strategies. The results of hierarchical multiple regression analysis show that self-efficacy and task value are significant predictors of the use of self-regulated learning strategies. There was a statistically significant difference in the use of self-regulated learning strategies between learners who possessed high self-efficacy and those who possessed low self-efficacy. In addition, learners who had high task value showed statistically significant higher average self-regulated learning scores than those who had low task value. Implications and future research directions are discussed based on the findings.
\end{abstract}

Keywords: self-regulated learning, self-efficacy, task value, massive open online courses, MOOCs, social cognitive perspective 


\section{Introduction}

Since the evolution of open educational resources (OER), massive open online courses (MOOCs) have emerged as a newplatform for online learning. MOOCs differ from traditional online courses, which "charge tuition, carry credit and limit enrollment to a few dozen to ensure interaction with instructors" (Pappano, 2012, p. 2), in several aspects; for example, MOOCs provide open access to education regardless of learners' previous experiences (Milligan \& Littlejohn, 2016), and their course structures consist of lecture videos, auto-graded quizzes, and online discussion forums (Glance, Forsey, \& Riley, 2013). In MOOCs, more than 1 million learners from all over the world are put into an online space where they complete tasks at their preferred pace (J ohnson, Becker, Estrada, \& Freeman, 2014). However, in MOOCs, there is a lack of interaction between instructors and learners, as well as the availability of significant learner support. These unique characteristics of MOOCs require learners to havean ability to self-regulate their own learning more than in traditional online courses.

Self-regulated learning (SRL) has been regarded as one of the vital factors positively affecting learners' success in traditional online learning environments (Cho \& Shen, 2013). In a recent systematic literature review study by Lee, Watson, and Watson (2019), it has been revealed that SRL positively influences learning in MOOCs as well. In addition, a broad range of learners participating in MOOCs commonly display self-efficacy and task value, as well as employ several SRL strategies to succeed in MOOCs (Lee et al., 2019). However, little is known about the relationships between self-efficacy, task value, and the use of SRL strategies in MOOCs. Studies on SRL in traditional online learning environments have shown that there are positive relationships between self-efficacy and the use of SRL strategies (e.g., Artino \& Stephens, 2006). Task value is also positively related to the use of SRL strategies (Hsu, 1997). These findings provide instructors and instructional designers with new insights on how to design online courses to support learners' self-regulation in terms of motivation and SRL strategies (e.g., Artino, 2008).

Several MOOC design principles or guidelines have been suggested as ways to support MOOClearners' SRL (e.g., Milligan \& Griffin, 2016; Nawrot \& Doucet, 2014). However, most have underestimated the motivational aspects of SRL such as self-efficacy and task value. For example, Nawrot and Doucet (2014) only focus on how to support MOOC learners' time management. This might be attributed to the use of different theoretical frameworks of SRL in the initial stage of research on SRL in MOOCs, such as Zimmerman and Pons's (1986) model, which focuses on other dimensions of SRL including seeking information (Lee et al., 2019) and thelack of understanding of the relationships among components of SRL. Therefore, the present study employed Zimmerman's (1989) social cognitive model, which has been widely used to examine the relationships in traditional online learning environments.

The purpose of this study is to examine the relationships between self-efficacy, task value, and SRL strategies in MOOCs from a social cognitive perspective. 


\section{Literature Review}

\section{SRL Strategies, Self-Efficacy, and Task Value in Traditional Online Learning Environments}

SRL is generally defined as "self-generated thoughts, feelings, and actions that are planned and cyclically adapted to the attainment of personal goals" (Zimmerman, 2000, p.14). SRL has been identified as a vital factor in positively influencing learners' success in online learning environments (Cho \&J onassen, 2009; Dabbagh \& Kitsantas, 2005). In a recent review of literature on SRL in online higher education settings published from 2004 to 2014, it was identified that SRL strategies, specifically time management, metacognition, effort regulation, and critical thinking, were positively correlated with academic outcomes (Broadbent \&Poon, 2015). In addition to SRL strategies, self-efficacy and task value have been regarded as important motivational beliefs for online learners' success. Self-efficacy refers to "people's beliefs about their capabilities to produce designated levels of performance that exercise influence over events that affect their lives" (Bandura, 1994, p. 71). The findings of review studies on self-efficacy in online settings indicate that self-efficacy is positively related to academic performance in online learning environments (Hodges, 2008; Tsai, Chuang, Liang, \&Tsai, 2011). Task value is defined as "students' evaluation of how interesting, how important, and how useful the task is" (Pintrich, Smith, Garcia, \&McKeachie, 1993, p. 11). The results of empirical studies show that task value is a positive predictor of learners' satisfaction with online courses (Artino, 2007a; Lee, 2002), as well as perceived learning and intentions to enroll in future online courses (Artino, 2007a).

\section{Social Cognitive Models of SRL}

With the importance of these factors in online learning environments, the relationships among them have received attention from researchers from a social cognitive perspective. According to social cognitive models of SRL, self-regulation is viewed as a triadic relationship among three processes: personal, behavioral, and environmental (Zimmerman, 1989). The models have been reinterpreted by researchers to fit with online environments because of social cognitive models of SRL being identified as applicable in several empirical studies on online learning environments (e.g., Artino, 2007b). According to researchers' reinterpretations of social cognitive models of SRL (Cho, Demei, \& Laffey, 2010; Wang \& Lin, 2007), motivational factors, specifically self-efficacy and task value, are commonly identified as personal influences on learning in online settings. Self-efficacy is especially emphasized as a key variable by social cognitive theorists (e.g., Bandura, 1986; Zimmerman, 1989). In addition, the use of SRL strategies, including cognitive and meta-cognitive strategies, is commonly found as a behavioral factor. Suggested environmental factors include peer/ teacher feedback, modeling, achievement (Wang \& Lin, 2007), social presence, and sense of community (Cho et al., 2010).

\section{The Relationships Between SRL Strategies, Self-Efficacy, and Task Value in Traditional Online Learning Environments}

Using social cognitive models of SRL as a theoretical framework, initial studies on SRL in traditional online learning environments have mainly explored the relationships between self-efficacy, task value, and SRL strategies (Artino, 2007b). They started with the aim of discerning whether relationships found in face-toface classroom settings are generalizable to online courses (Whipp \& Chiarelli, 2004). The findings of 
several studies on SRL in the context of middle school and college classrooms show students' self-efficacy and task value to be positively related to their use of SRL strategies (e.g., Pintrich, 1999; Pintrich \&DeGroot, 1990). Based on thesefindings, Pintrich (1999) has concluded that self-efficacy and task value help students promote and sustain SRL. The role of self-efficacy and task value in self-regulatory processes is also shown in Zimmerman's (2002) model of three cyclical phases of SRL proposed from a social cognitive perspective. For instance, in the first phase of self-regulatory processes, students' self-efficacy and task value start with the use of learning strategies, including goal setting and strategic planning (Zimmerman, 2002).

The findings of studies on SRL in traditional online learning environments parallel those in face-to-face classroom, indicating that self-efficacy is positively related to the use of SRL strategies (e.g., Artino \&J ones, 2012; Artino \& Stephens, 2006; Cho \& Shen, 2013; J oo, Bong, \& Choi, 2000; Shea \& Bidjerano, 2010). For example, Cho and Shen (2013) found positive correlations between self-efficacy and SRL strategies, including metacognitive regulation and interaction regulation, by administering surveys with 64 students who were taking an online course delivered via Blackboard. Shea and Bidjerano (2010) also discovered a positive correlation between self-efficacy and effort regulation strategy through the analysis of survey responses of 2,418 students who had taken online courses. These findings show that the more selfefficacious students are, the more likely they are to use SRL strategies in traditional online courses. In addition, it was revealed that online learners' self-efficacy was a significantly positive predictor of their use of cognitive strategies (Artino \&J ones, 2012; J oo et al., 2000). These findings align with the finding that students' self-efficacy beliefs are a predictor of how they behave (Pajares, 2002).

Task value is also positively related to the use of SRL strategies in traditional online learning settings (e.g., Artino \& Jones, 2012; Artino \& Stephens, 2006; Hsu, 1997). For example, Hsu (1997) found positive correlations between task value and metacognition, time and environment management, and effort regulation and help-seeking strategies in 169 online learners. Artino and Stephens (2006) also discovered positive correlations between online learners' task value and their use of cognitive strategies, including elaboration and critical thinking, and metacognitive strategies. The more students believe that tasks in online courses are interesting, important, or useful, the more likely they are to use SRL strategies. In addition, study findings show that task value is a significantly positive predictor of use of SRL strategies (Artino \&J ones, 2012; Artino \&Stephens, 2006). For example, task value has been revealed as a significant positive predictor of elaboration, critical thinking, and metacognition strategies (Artino \& Stephens, 2006).

The relationships between self-efficacy, task value, and use of SRL strategies found in traditional online learning settings offer newinsights on how to design online courses to support students' SRL. Online course instructors, as well as instructional designers, recognize that SRL is important for students to succeed in online learning (Kim \& Bonk, 2006). However, little has been found about how to support online learners' SRL. Based on study findings about the relationships between self-efficacy, task value, and use of SRL strategies, the importance of roles that motivation such as self-efficacy and task value play in SRL processes (Pintrich, 1999; Schunk \&Zimmerman, 1998) as well as how they relate to use of SRL strategies have been considered in designing online courses. For example, Artino (2008) provided online instructors with practical guidelines for supporting students' SRL based on the findings of empirical studies between 1995 and 2007. One of the guidelines was to develop and support students' self-efficacy, clarifying task relevance and design activities that are grounded in authentic problems to generate interest. 


\section{SRL Strategies, Self-Efficacy, and Task Value in MOOCs}

Since the evolution of OER, MOOCs have emerged as a new platform for online learning. MOOCs are different from traditional online courses in several aspects. They provide open access to education for all applicants regardless of their previous qualifications or experiences (Milligan \& Littlejohn, 2016), typically without registration fees, except for learners pursuing verified certification (Schulze, 2014). In addition, MOOCs promote online learning at a massive scale by attracting millions of learners (Milligan \&Littlejohn, 2016). In terms of course structure, most MOOCs consist of lecture videos, auto-graded quizzes, and online discussion forums (Glance et al., 2013). A broad range of learners with different backgrounds enroll in MOOCs with diverse motivations. They complete tasks in MOOCs at their preferred pace without following linear learning paths (J ohnson et al., 2014). However, individual learners who take MOOCs should be more autonomous than those who take traditional online courses. This is because they need to determine which learning activities they will participate in and when and how they will complete them (Milligan \&Littlejohn, 2016). The lack of instructor support (Kizilcec, Pérez-Sanagustín, \& Maldonado, 2017) as well as limited social interaction (Gasevic, Kovanovic, J oksimovic, \& Siemens, 2014) require learners to have an ability to self-regulate their own learning in MOOCs.

A recent systematic review on empirical studies on SRL in MOOCs has demonstrated the importance of SRL, showing that it has positive effects on MOOC learning (Lee et al., 2019). In the review, it was revealed that a broad range of MOOC learners have self-efficacy and task value beliefs and employ several SRL strategies such as time management. In a recent study, 6,335 MOOC learners reported high self-efficacy and task value scores and high critical thinking scores in the Motivated Strategies for Learning Questionnaire (MSLQ) (Alario-Hoyos, Estévez-Ayres, Pérez-Sanagustín, Kloos, \& Fernández-Panadero, 2017). In addition, learners who completed a MOOC reported that effort regulation strategy was the most important SRL strategy to succeed in a MOOC (Kizilcec, Pérez-Sanagustín, \& Maldonado, 2016). Although self-efficacy, task value, and SRL strategies have been commonly identified in empirical studies on MOOCs, little has been known about the relationships among them.

The relationships between self-efficacy, task value, and use of SRL strategies could provide new insights on how to design MOOCs to support learners' self-regulation with MOOC instructors and instructional designers as they did in traditional online learning environments. Several MOOC design principles or guidelines have been suggested to better support MOOC learners' self-regulation (e.g., Milligan \& Griffin, 2016; Nawrot \& Doucet, 2014). However, motivational aspects of SRL such as self-efficacy and task value have been underestimated in supporting learners' SRL in MOOC environments. This might be attributed to the use of different theoretical frameworks of SRL (Lee et al., 2019), such as Zimmerman and Pons's (1986) model that mainly focuses on other dimensions of SRL strategies including seeking information, and the lack of research on the relationships among components of SRL in MOOCs. Therefore, the present study addresses this gap by adopting Zimmerman's (1989) social cognitive model of SRL, which has been widely used in traditional online learning environments.

The research questions and hypotheses in this study were as follows:

RQ1. Are there relationships between learners' self-efficacy and their use of SRL strategies in MOOCs? 
H1. Self-efficacy will positively correlate with the use of SRL strategies of MOOC learners.

H2. Self-efficacy will significantly predict MOOC learners' use of SRL strategies.

H3. There will be a significant difference in the use of SRL strategies between MOOC learners with high self-efficacy and those with low self-efficacy.

RQ2. Are there relationships between learners' task value and their use of SRL strategies in MOOCs?

H4. Task value will positively correlate with the use of SRL strategies of MOOC learners.

H5. Task value will significantly predict MOOC learners' use of SRL strategies.

H6. There will be a significant difference in the use of SRL strategies between MOOC learners with high task value and those with low task value.

\section{Methods}

\section{Study Setting}

This study was conducted on two self-paced probability MOOCs. The courses were offered by a large Midwestern university on the edX platform. The first MOOC, titled Probability: Basic Concepts \& Discrete Random Variables, provided an introduction to mathematical probability. The second MOOC, titled Probability: Distribution Models \& Continuous Random Variables, addressed continuous random variables and probability distribution models. The MOOCs were fully delivered online, and the same professor taught both. Each MOOC consisted of six units with video lectures, quizzes, examples, and practice activities. The units were designed to be completed according to the suggested schedule of one unit per week. However, students could study and complete each unit at their own pace. They could enroll in each MOOC anytime for free. If they wanted to earn a verified certificate, they could pay a small fee. The research team had no affiliation with the MOOC instructor or the edX platform institution.

\section{Instruments}

A total of seven self-efficacy items and six task value items from the MSLQ were used (Pintrich et al., 1991). MSLQ is one of the most well-known instruments used to measure online learners' self-efficacy and task value, as shown in literature reviews of SRL in traditional online settings (Artino, 2007b; Broadbent \&Poon, 2015). Therefore, it has been increasingly used in MOOC environments (e.g., Alario-Hoyos et al., 2017). The items were slightly modified to better fit with MOOC environments. For example, the item 'I'm confident I can do an excellent job on the assignments and tests in this course" was modified to "I'm confident I can do an excellent job on the assignments and quizzes in this MOOC." The items were rated on a 7-point Likert scale ranging from "not at all true of me" to "very true of me." In this study, the reliability with Cronbach's $\alpha$ values of self-efficacy and task value were .91 and .87 , respectively. 
The use of SRL strategies was measured by the Online Self-Regulated Learning Questionnaire (OSLQ) from Barnard, Lan, To, Paton, and Lai (2009), which consists of 24 items with a 5-point Likert scale ranging from "strongly agree" to "strongly disagree." The OSLQ has been widely used to measure students' SRL strategies in traditional online learning settings (e.g., Barnard-Brak, Paton, \&Lan, 2010). Researchers have recently used it to measure students' use of SRL strategies in MOOC environments (e.g., Ohan \& Sinclair, 2016). The OSLQ consists of six subscales: environment structuring, goal setting, time management, help seeking, task strategies, and self-evaluation. In the items, the word online courses was changed to MOOC to better fit MOOC environments. The reliability with Cronbach's a values of OSLQ in this study was .93. The content validity of self-efficacy items, task value items, and OSLQ was verified through content-related evidence by two professors of educational technology who evaluated the modified items and decided whether they adequately represented the content domain. According to J ohnson and Christensen (2017), content-related evidence is "validity evidence based on a judgement of the degree to which the items, tasks, or questions on a test adequately represent the construct domain of interest" (p. 172) and must be done by experts.

\section{Recruitment and Respondents}

Once Institutional Review Board approval was granted, a survey link was posted on the MOOCs' message boards by the MOOC instructor as an announcement. Students were asked to complete the survey while taking the MOOCs if they were interested in participating in this study. The survey was voluntary, and there was no incentive for students to complete it. The survey responses were collected in 2018 from the spring semester through the fall semester.

A total of 13,465 learners enrolled in the two probability MOOCs. Of the 13,465 learners, 242 responded to the survey. However, 50 people skipped at least one question about self-efficacy, task value, and OSLQ. Their responses were excluded from data analysis. In addition, eight outliers were detected and removed. Finally, 184 learners from 37 countries completed the survey. The age of 184 learners ranged from 18 to 66 years and above: 60 learners were 18-25 years of age (32.6\%); 56 learners were 26-35 years of age (30.4\%); 38 learners were 36-45 years of age (20.7\%); 12 learners were $46-55$ years of age (6.5\%); 13 learners were $56-65$ years of age ( $7.1 \%)$; and 5 learners were over 66 years of age (2.7\%). In terms of gender, 130 learners were male (70.7\%) and 54 learners were female (29.3\%).

\section{Data Analysis}

The data sets were analyzed by using SPSS statistical software. In order to test hypotheses 1 and 4, Pearson's correlation analysis was conducted. Hierarchical multiple regression analysis was conducted to test hypotheses 2 and 5. Since Zimmerman's (1989) social cognitive model of SRL emphasizes self-efficacy as a key variable positively affecting self-regulatory processes, a hierarchical multiple regression model where the order of the predictor variables is determined based on the theory was used. In order to test hypotheses 3 and 6, two separate independent sample t-tests were conducted. All assumptions for Pearson's correlation, multiple linear regression, and independent sample t-test were checked and satisfied. They are represented in the following section. 


\section{Results}

\section{Results of Pearson's Correlation Analysis}

All assumptions for Pearson's correlation were first checked and met. The Kolmogorov-Smirnov and Shapiro-Wilk tests results showed that the residuals were normally distributed $(p>.05)$. Scatterplot graphs confirmed a linear relationship between self-efficacy, task value, and SRL strategies. The BreuschPagan test (Breusch \& Pagan, 1979) result showed no homoscedasticity ( $p>.05)$. Scatterplot graphs also confirmed that homoscedasticity did not exist.

The results of Pearson's correlation analysis showed that self-efficacy was positively related to probability MOOC learners' use of SRL strategies $(r=.36, p<.01)$, which supports hypothesis 1 . Pearson's correlation analysis was also revealed that task value was positively related to probability MOOC learners' use of SRL strategies $(r=.45, \mathrm{p}<.01)$, which supports hypothesis 4 . Table 1 represents descriptive statistics and the results of Pearson correlation analysis.

Table 1

Means, Standard Deviations, and Pearson's Correlations for Self-Efficacy, Task Value, and SelfRegulated Learning

\begin{tabular}{|lccccc|}
\hline Variable & M & SD & Self-efficacy & Task value & SRL \\
\hline Self-efficacy & 5.35 & .95 & - & $.52^{* *}$ & $.36^{* *}$ \\
Task value & 5.92 & .78 & $.52^{* *}$ & - & $.45^{* *}$ \\
SRL & 3.54 & .68 & $.36^{* *}$ & $.45^{* *}$ & - \\
\hline
\end{tabular}

Note. $\mathrm{M}=$ mean; $\mathrm{SD}=$ standard deviation; $\mathrm{SRL}=$ self-regulated learning.

$* * \mathrm{p}<.01$.

\section{The Results of Hierarchical Multiple Regression Analysis}

Two-step hierarchical multiple regression analysis was carried out with an entrance level of 0.05 and an exclusion level of 0.10 to test hypotheses 2 and 5. Prior to conducting hierarchical multiple regression analysis, all assumptions for multiple linear regression were checked and met. As shown in Pearson's correlation analysis, normality and linearity were met, and there was no homoscedasticity. Multicollinearity was checked by variance inflation factor values, which were lower than 10 , indicating no strong correlation between self-efficacy and task value. Finally, the Durbin-Watson statistic was 1.71, indicating that there were no independent errors by the residuals.

The results of hierarchical multiple regression analysis are shown in Table 2. In model 1, self-efficacy was entered based on Zimmerman's (1989) social cognitive model of SRL, which emphasizes the importance of self-efficacy. Model 1 was statistically significant $(F(1,182)=27.18, p<.01)$ and accounted for 
approximately $13 \%$ of the variance of SRL strategies $\left(\mathrm{R}^{2}=.13\right.$, adjusted $\left.\mathrm{R}^{2}=.13\right)$. Self-efficacy was found to be a significant predictor of SRL strategies $(\beta=.36, \mathrm{p}<.05$ ). Model 2 including task value was statistically significant $(\mathrm{F}(2,181)=25.78, \mathrm{p}<.01)$ and accounted for approximately $21 \%$ of the variance of SRL strategies $\left(\mathrm{R}^{2}=.22\right.$, adjusted $\left.\mathrm{R}^{2}=.21\right)$. Task value $(\beta=.36, \mathrm{p}<.05)$ and self-efficacy $(\beta=.17, \mathrm{p}<.05)$ were all found to be significant predictors of SRL strategies. Therefore, both hypothesis 2 and hypothesis 5 are supported.

Table 2

Results of Hierarchical Multiple Regression Analysis

\begin{tabular}{|lllllll|}
\hline \multirow{2}{*}{ Variable } & \multicolumn{7}{c}{ Model 1 } & \multicolumn{5}{c|}{ Model 2 } \\
\cline { 2 - 6 } & B & SE & $\beta$ & B & SE & $\beta$ \\
\hline Self-efficacy & .26 & .05 & $.36^{* *}$ & .12 & .06 & $.17^{* *}$ \\
Task value & & & & .30 & .07 & $.36^{* *}$ \\
$\mathrm{R}^{2}$ & & & .20 & & & .22 \\
Adjusted $\mathrm{R}^{2}$ & & & .20 & & .21 \\
$\Delta \mathrm{R}^{2}$ & & .13 & & .01 \\
$\mathrm{~F}$ & & & & & $25.78^{*}$ \\
\hline
\end{tabular}

Note. $\mathrm{B}=$ unstandardized beta; $\mathrm{SE}=$ standard error.

$* \mathrm{p}<.01$. ** $\mathrm{p}<.05$.

\section{The Results of Independent Sample $t$-Test}

Before testing hypotheses 3 and 6, all assumptions for the independent sample t-test were checked. The Kolmogorov-Smirnov test and the Shapiro- Wilk test results showed that the residuals were normally distributed ( $p>$.05). The assumption of homogeneity of variance was met by Levene's test of equality of variances $(F=2.21, p>.05 ; F=3.07, p>.05)$. MOOC learners were divided into three level groups according to percentile based on their self-efficacy and task value scores: the low group was below the 25th percentile; the medium group was between the 25th and the 75th percentile; the high group was above the 75th percentile.

As shown in Table 3, the results of an independent sample t-test indicated a statistically significant difference in the average total scores of SRL between probability MOOC learners who had high levels of self-efficacy $(\mathrm{M}=6.61, \mathrm{SD}=.34)$ and those who had low levels of self-efficacy $(\mathrm{M}=4.15, \mathrm{SD}=.44)$, $\mathrm{t}(87)=-5.31, \mathrm{p}=.00$. Hence, hypothesis 3 is supported. 
Table 3

Results of Independent Sample t-Test and Descriptive Statistics for Self-Regulated Learning Scores by Self-Efficacy Levels

\begin{tabular}{|c|c|c|c|c|c|c|c|c|c|c|}
\hline & & & Self & acy le & & & & & & \\
\hline & Low & -effica & & High & E-effic & & $95 \%$ CI for & $\mathrm{t}$ & $\mathrm{df}$ & $\mathrm{p}$ \\
\hline & $\mathrm{M}$ & SD & $\mathrm{n}$ & $\mathrm{M}$ & SD & $\mathrm{n}$ & difference & & & \\
\hline SRL & 4.15 & 0.44 & 49 & 6.61 & 0.34 & 40 & $-.98,-.45$ & -5.31 & 87 & $.00^{*}$ \\
\hline
\end{tabular}

Note. $\mathrm{M}=$ mean; $\mathrm{SD}=$ standard deviation; $95 \% \mathrm{CI}=95 \%$ confidence interval; SRL =self-regulated learning. $* \mathrm{p}<.05$.

In addition, there was a statistically significant difference in the mean scores of SRL between probability MOOC learners who had high task value $(\mathrm{M}=6.86, \mathrm{SD}=.14)$ and those who had low task value $(\mathrm{M}=4.83$, $\mathrm{SD}=.38), \mathrm{t}(91)=-6.00, \mathrm{p}=.00$. Therefore, hypothesis 6 is supported. Table 4 shows the results of the independent sample t-test for SRL scores by task value levels.

Table 4

Results of Independent Sample t-Test and Descriptive Statistics for Self-Regulated Learning Scores by Task Value Levels

\begin{tabular}{|c|c|c|c|c|c|c|c|c|c|c|}
\hline & \multicolumn{6}{|c|}{ Task value level } & \multirow{3}{*}{$\begin{array}{l}\text { 95\% CI for } \\
\text { mean } \\
\text { difference }\end{array}$} & \multirow{3}{*}{$\mathrm{t}$} & \multirow{3}{*}{$\mathrm{df}$} & \multirow{3}{*}{$\mathrm{p}$} \\
\hline & \multicolumn{2}{|c|}{ Low task value } & & \multicolumn{3}{|c|}{ High task value } & & & & \\
\hline & $\mathrm{M}$ & SD & $\mathrm{n}$ & $\mathrm{M}$ & SD & $\mathrm{n}$ & & & & \\
\hline SRL & 4.83 & 0.38 & 43 & 6.86 & 0.14 & 50 & $-1.09,-.55$ & -6.00 & 91 & $.00 *$ \\
\hline
\end{tabular}

Note. $\mathrm{M}=$ mean; $\mathrm{SD}=$ standard deviation; $95 \% \mathrm{CI}=95 \%$ confidence interval; SRL = self-regulated learning. $* \mathrm{p}<.05$.

\section{Discussion}

This study examined the relationships between self-efficacy, task value, and the use of SRL strategies in MOOCs using Zimmerman's (1989) social cognitive model of SRL. The understanding of the relationships between self-efficacy, task value, and SRL strategies in MOOCs is still nascent, which has resulted in limited application in MOOC design and teaching to support self-regulation of MOOC learners with heterogenous 
backgrounds and experiences. This study marks the first step in applying a social cognitive model of SRL to MOOC environments and extending the relationships found in traditional online courses to MOOCs.

\section{RQ1. Are There Relationships Between Learners' Self-Efficacy and Their Use of SRL Strategies in MOOCs?}

The study findings demonstrate that self-efficacy was positively associated with the use of SRL strategies in two probability MOOCS as found in traditional onlinelearning settings. A positive correlation between selfefficacy and the use of SRL strategies in the MOOCs is consistent with findings of previous studies on SRL in traditional online courses (e.g., Cho \& Shen, 2013; Shea \& Bidjerano, 2010). The more that probability MOOClearners are self-efficacious, the more likely they are to use SRL strategies. In model 1 of hierarchical multiple regression, it was revealed that self-efficacy significantly and positively predicted the use of SRL strategies of the probability MOOC learners. When task value was added in model 2, self-efficacy was still a significant predictor of the use of SRL strategies in the MOOCS. These study findings are congruent with previous study findings showing self-efficacy as a significant predictor of SRL strategies in traditional online courses (Artino \&J ones, 2012; J oo et al., 2000). In addition, the statistically significant higher average SRL scores of the probability MOOC learners with high self-efficacy support Pintrich's (1999) assertation that self-efficacy promotes SRL behaviors. In summary, although there are differences between traditional online courses and MOOCs such as course structure (e.g., Glance et al., 2013), positive relationships between self-efficacy and SRL strategies found in previous studies on traditional online courses extended to the context of MOOCs studied here. Self-efficacy positively affected use of SRL strategies in the probability MOOC learners, which indicates self-efficacy playing a key role in promoting learners' SRL strategies in MOOCs.

\section{RQ2. Are There Relationships Between Learners' Task Value and Their Use of SRL Strategies in MOOCs?}

Task value was positively related to the use of SRL strategies in two probability MOOCs, as found in traditional online course settings. There was a positive correlation between task value and the use of SRL strategies in the probability MOOCs studied here, which is congruent with previous research findings in traditional online courses (e.g., Artino \& Stephens, 2006; Hsu, 1997). Students who believed that the materials in the two probability MOOCs were useful and that understanding the MOOC subjects was important were more likely to use SRL strategies. In model 2 of hierarchical multiple regression, it was revealed that task value significantly and positively predicted the MOOC learners' use of SRL strategies. These findings are consistent with those from earlier studies showing that task value is a significant predictor of SRL strategies in traditional online courses (Artino \&J ones, 2012; Artino \& Stephens, 2006; J oo et al., 2000). In addition, the statistically significant higher average SRL scores of the probability MOOC learners with high task value support Pintrich's (1999) assertation that task value fosters SRL behaviors. In summary, despite differences between traditional online courses and MOOCs, such as openness (Schulze, 2014) and course goals (Perna et al., 2014), the positive relationships between task valueand SRL strategies found in previous studies on traditional online learning settings (e.g., Artino \& Jones, 2012; Artino \& Stephens, 2006) extended to the context of MOOCs studied here. Task value positively affected use of SRL strategies in the two probability MOOC learners, which indicates the importance of task value to promote learners' SRL strategies in MOOCs. 


\section{Implications for Practice}

The results reported here have practical implications. MOOCs differ from traditional online courses in several aspects, such as lectures formatted as short videos, formative quizzes, and online forums (Glance et al., 2013). The relationships between self-efficacy and SRL strategies found in this study suggest that, considering the unique characteristics of MOOCs, MOOC practitioners should help learners improve their self-efficacy. For example, MOOC instructors could regularly show learners their learning progress through system-generated e-mail notifications as self-perceptions of progress improve learners' self-efficacy beliefs (Ertmer, Newby, \& MacDougall, 1996). In addition, as Hodges (2016) has suggested, MOOC instructors could provide persuasive feedback on quizzes rather than simple feedback such as "correct" or "incorrect" in order to better develop learners' self-efficacy. The relations between task value and SRL strategies found here suggest that MOOCinstructors or instructional designers should help learners improvetheir task value or keep their task value high. There is a need to improve the instructional design quality of MOOCs based on instructional design principles (Margaryan, Bianco, \& Littlejohn, 2015), which helps MOOC learners place a value on high quality MOOC resources or activities.

\section{Limitations and Future Research}

This study has a number of limitations. First, only a single topic of probability was investigated, although across two MOOCs. Other MOOCs on the same topic as well as on different topics should befurther explored for a better understanding of the relationships between MOOC learners' self-efficacy, task value, and SRL strategies. Second, the scope of this study was limited to relationships between self-efficacy and task value as personal variables and SRL strategy as a behavioral variable in the framework of Zimmerman's (1989) social cognitive model of SRL. Future research should explore other behavioral variables and environmental variables, as well as the relationships among them. Third, the data in this study were derived from selfreported questionnaires. Although these methods have been widely used in empirical research on SRL in traditional online settings (Artino, 2007b), the employment of qualitative methods could enrich the findings of this study by more deeply exploring individuals' use of SRL strategies and their relation to users' self-efficacy and task value beliefs. Finally, this study investigated only the total SRL scores of MOOC learners. Future research should examine SRL subscales to better understand the differences in the use of SRL strategies among MOOC learners with different levels of self-efficacy and task value.

\section{Conclusions}

This study investigated the relationships between self-efficacy, task value, and SRL strategies of MOOC learners from a social cognitive perspective. The results of this study show positive relationships between self-efficacy and SRL strategies in two probability MOOCs. In addition, positive relationships between task value and SRL strategies were found in the two MOOCs. This study sheds new light on research on MOOCs by revealing the applicability of using a social cognitive model of SRL (Zimmerman, 1989) in MOOCs and providing empirical evidence on the relationships between self-efficacy, task value, and SRL strategies in MOOCs. In addition, the findings of the present study highlight the key role of learners' self-efficacy and task value in self-regulatory processes in MOOCs and the necessity of supporting them. 


\section{References}

Alario-Hoyos, C., Estévez-Ayres, I., Pérez-Sanagustín, M., Kloos, C. D., \&Fernández-Panadero, C. (2017). Understanding learners' motivation and learning strategies in MOOCs. The International Review of Research in Open and Distributed Learning, 18(3). https:// doi.org/ 10.19173/irrodl.v18i3.2996

Artino, A. R. (2007a). Online military training: Using a social cognitive view of motivation and selfregulation to understand students' satisfaction, perceived learning, and choice. Quarterly Review of Distance Education, 8(3), 191.

Artino, A. R. (2007b). Self-regulated learning in online education: A review of the empirical literature. International J ournal of Instructional Technology and Distance Learning, 4(6), 3-18.

Artino, A. R. (2008). Promoting academic motivation and self-regulation: Practical guidelines for online instructors. TechTrends, 52(3), 37-45. https:// doi.org/ 10.1007/s11528-008-0153-X

Artino, A. R., \&J ones, K. D. (2012). Exploring the complex relations between achievement emotions and self-regulated learning behaviors in online learning. The Internet and Higher Education, 15(3), 170-175. https:// doi.org/ 10.1016/j.iheduc.2012.01.006

Artino, A. R., \& Stephens, J . M. (2006). Learning online: Motivated to self-regulate? Academic Exchange Quarterly, 10(4), 176-182. Retrieved from https:// www.researchgate.net/publication/267362438_Learning_Online_Motivated_to_SelfRegulate

Bandura, A. (1986). Social foundations of thought and action: A social cognitive theory. Englewood Cliffs, NJ : Prentice-Hall.

Bandura, A. (1994). Self-efficacy. In V. S. Ramachaudran (Ed.), Encyclopedia of human behavior (pp. $71-$ 81). New York, NY: Academic Press.

Barnard, L., Lan, W. Y., To, Y. M., Paton, V. O., \&Lai, S. L. (2009). Measuring self-regulation in online and blended learning environments. The Internet and Higher Education, 12(1), 1-6. https:// doi.org/ 10.1016/j.iheduc.2008.10.005

Barnard-Brak, L., Paton, V. O., \& Lan, W. Y. (2010). Profiles in self-regulated learning in the online learning environment. The International Review of Research in Open and Distributed Learning, 11(1), 61-80. https:// doi.org/ 10.19173/irrodl.v11i1.769

Breusch, T. S., \& Pagan, A. R. (1979). A simple test for heteroscedasticity and random coefficient variation. Econometrica: J ournal of the Econometric Society, 47(5), 1287-1294.

https:// doi.org/ 10.2307/ 1911963 
Broadbent, J ., \& Poon, W. L. (2015). Self-regulated learning strategies \& academic achievement in online higher education learning environments: A systematic review. The Internet and Higher Education, 27, 1- 13. https:// doi.org/ 10.1016/j.iheduc.2015.04.007

Cho, M. H., Demei, S., \&Laffey, J . (2010). Relationships between self-regulation and social experiences in asynchronous online learning environments. J ournal of Interactive Learning Research, 21(3), 297-316. Retrieved from https:// www.learntechlib.org/ p/ 29491

Cho, M. H., \&J onassen, D. (2009). Development of the human interaction dimension of the SelfRegulated Learning Questionnaire in asynchronous online learning environments. Educational Psychology, 29(1), 117-138. https:// doi.org/ 10.1080/01443410802516934

Cho, M., \& Shen, D. (2013). Self-regulation in online learning. Distance Education, 34(3), 290- 301. https:// doi.org/ 10.1080/01587919.2013.835770

Dabbagh, N., \& Kitsantas, A. (2005). Using Web-based pedagogical tools as scaffolds for self-regulated learning. Instructional Science, 33(5-6), 513-540. https:// doi.org/ 10.1007/s11251-005-1278-3

Ertmer, P. A., Newby, T. J ., \& MacDougall, M. (1996). Students' responses and approaches to case-based instruction: The role of reflective self-regulation. American Educational Research J ournal, 33, 719-752. https:// doi.org/ 10.3102/00028312033003719

Gasevic, D., Kovanovic, V., J oksimovic, S., \& Siemens, G. (2014). Where is research on massive open online courses headed? A data analysis of the MOOC Research Initiative. The International Review of Research in Open and Distributed Learning, 15(5). https:// doi.org/ 10.19173/irrodl.v15i5.1954

Glance, D. G., Forsey, M., \& Riley, M. (2013). The pedagogical foundations of massive open online courses. First Monday, 18(5). https:// doi.org/ 10.5210/ fm.v18i5.4350

Hodges, C. B. (2008). Self-efficacy in the context of online learning environments: A review of the literature and directions for research. Performance Improvement Quarterly, 20(3-4), 7-25. https:// doi.org/ 10.1002/ piq.20001

Hodges, C. (2016). The development of learner self-efficacy in MOOCs. In P. Kirby \&G. Marks (Eds.), Proceedings of Global Learn 2016-Global conference on learning and technology (pp. 517-522). Retrieved from https:// www.learntechlib.org/p/ 172763

Hsu, J . T. (1997). Value, expectancy, metacognition, resource management, and academic achievement: A structural model of self-regulated learning in a distance education context (Doctoral dissertation). Retrieved from https:// www.learntechlib.org/p/120360/

Johnson, B., \& Christensen, L. (2017). Educational research: Quantitative, qualitative, and mixed approaches (6th ed.). Thousand Oaks, CA: Sage Publications. 
Johnson, L., Becker, S., Estrada, V., \&Freeman, A. (2014). NMC Horizon report: 2014 higher education edition. Austin, TX: New Media Consortium.

J oo, Y., Bong, M., \& Choi, H. (2000). Self-efficacy for self-regulated learning, academic self-efficacy, and Internet self-efficacy in Web-based instruction. Educational Technology Research and Development, 48(2), 5-17. https:/ / doi.org/ 10.1007/BF02313398

Kim, K. J ., \& Bonk, C. J . (2006). The future of online teaching and learning in higher education: The survey says. Educause Quarterly, 29(4), 22-30. Retrieved from https:// er.educause.edu/articles/2006/ 1/the-future-of-online-teaching-and-learning-in-highereducation-the-survey-says

Kizilcec, R. F., Pérez-Sanagustín, M., \& Maldonado, J . J . (2016, April). Recommending self-regulated learning strategies does not improve performance in a MOOC. Paper presented at Learning@Scale 2016, Edinburgh. https:// doi.org/ 10.1145/ 2876034.2893378

Kizilcec, R. F., Pérez-Sanagustín, M., \& Maldonado, J . J . (2017). Self-regulated learning strategies predict learner behavior and goal attainment in massive open online courses. Computers \& Education, 104, 18- 33. https:// doi.org/ 10.1016/j.compedu.2016.10.001

Lee, C. Y. (2002). The impact of self-efficacy and task value on satisfaction and performance in a Webbased course (Unpublished doctoral dissertation). University of Central Florida, Orlando, FL.

Lee, D., Watson, S. L., \&Watson, W. R. (2019). Systematic literature review on self-regulated learning in massive open online courses. Australasian J ournal of Educational Technology, 35(1), 28-41. https:// doi.org/ 10.14742/ ajet.3749

Margaryan, A., Bianco, M., \& Littlejohn, A. (2015). Instructional quality of massive open online courses (MOOCs). Computers \& Education, 80, 77-83. https:// doi.org/ 10.1016/j.compedu.2014.08.005

Milligan, C., \& Littlejohn, A. (2016). How health professionals regulate their learning in massive open online courses. The Internet and Higher Education, 31, 113-121. https:// doi.org/ 10.1016/j.iheduc.2016.07.005

Milligan, S. K., \& Griffin, P. (2016). Understanding learning and learning design in MOOCs: A measurement-based interpretation. J ournal of Learning Analytics, 3(2), 88- 115. https:// doi.org/ 10.18608/jla.2016.32.5

Nawrot, I., \& Doucet, A. (2014, April). Building engagement for MOOC students: Introducing support for time management on online learning platforms. Paper presented at the 23rd International World Wide Web Conference, Seoul, South Korea. https:// doi.org/ 10.1145/ 2567948.2580054

Onah, D. F. O, \& Sinclair, J . E. (2016, September). A multi-dimensional investigation of self-regulated learning in a blended classroom context: A case study on eLDa MOOC. In M. E. Auer, G. Guralnick, \&J. Uhomoibhi (Eds.), Proceedings of the 19th International Conference on 
The Relationships Between Self-Efficacy, Task Value, and Self-Regulated Learning Strategies in Massive Open Online Courses Lee, Watson, and Watson

Interactive Collaborative Learning (pp. 63- 85). Springer. http:// doi.prg/ 10.1007/978-3-319$\underline{50340-0}$

Pajares, F. (2002). Overview of social cognitive theory and of self-efficacy. Received from http:// people.wku.edu/ richard.miller/ banduratheory.pdf

Pappano, L. (2012, November 2). The year of the MOOC. The New York Times. Retrieved from https:// www.edinaschools.org/cms/lib/ MN01909547/ Centricity/ Domain/ 272/ The\%20Year\%20 of\%20the\%20MOOC\%20NY\%20Times.pdf

Perna, L. W., Ruby, A., Boruch, R. F., Wang, N., Scull, J ., Ahmad, S., \& Evans, C. (2014). Moving through MOOCs: Understanding the progression of users in massive open online courses. Educational Researcher, 43(9), 421- 432. https:// doi.org/ 10.3102/0013189X14562423

Pintrich, P. R. (1999). The role of motivation in promoting and sustaining self-regulated learning. International J ournal of Educational Research, 31(6), 459-470. https:// doi.org/ 10.1016/ S0883$\underline{0355(99) 00015-4}$

Pintrich, P. R., \&De Groot, E. V. (1990). Motivational and self-regulated learning components of classroom academic performance. J ournal of Educational Psychology, 82(1), 33-40. https:// doi.org/ 10.1037/ 0022-0663.82.1.33

Pintrich, P. R., Smith, D. A. F., Garcia, T., \& McKeachie, W. J . (1991). A manual for the use of the Motivated Strategies for Learning Questionnaire (MSLQ). Ann Arbor, MI: The University of Michigan.

Pintrich, P. R., Smith, D. A., Garcia, T., \& McKeachie, W. J . (1993). Reliability and predictive validity of the Motivated Strategies for Learning Questionnaire (MSLQ). Educational and Psychological Measurement, 53(3), 801-813. http:// doi.org/ 10.1177/0013164493053003024

Schulze, A. S. (2014). Massive open online courses (MOOCs) and completion rates: Are self-directed adult learners the most successful at MOOCs? (Doctoral dissertation, Pepperdine University). Retrieved from https:// pqdtopen.proquest.com/ pubnum/ 3622996.html

Schunk, D. H., \&Zimmerman, B. J . (1998). Self-regulated learning: From teaching to self-reflective practice. New York, NY: Guilford Press.

Shea, P., \& Bidjerano, T. (2010). Learning presence: Towards a theory of self-efficacy, self-regulation, and the development of a communities of inquiry in online and blended learning environments. Computers \&Education, 55(4), 1721-1731. https:// doi.org/ 10.1016/j.compedu.2010.07.017

Tsai, C. C., Chuang, S. C., Liang, J . C., \& Tsai, M. J . (2011). Self-efficacy in Internet-based learning environments: A literature review. J ournal of Educational Technology \& Society, 14(4). Retrieved from http:// www.jstor.org/ stable/jeductechsoci.14.4.222 
Wang, S. L., \&Lin, S. S. (2007). The application of social cognitive theory to Web-based learning through NetPorts. British J ournal of Educational Technology, 38(4), 600-612. https:// doi.org/ 10.1111/j.1467-8535.2006.00645.x

Whipp, J . L., \& Chiarelli, S. (2004). Self-regulation in a Web-based course: A case study. Educational Technology Research and Development, 52(4), 5-22. https:// doi.org/ 10.1007/BF02504714

Zimmerman, B. J . (1989). A social cognitive view of self-regulated academic learning. J ournal of educational psychology, 81(3), 329-339. https:// doi.org/ 10.1037/ 0022-0663.81.3.329

Zimmerman, B. J . (2000). Attaining self-regulation: A social cognitive perspective. In M. Boekaerts, P. Pintrich, \& M. Zeidner (Eds.), Handbook of self-regulation (pp. 13-39). San Diego, CA: Academic Press.

Zimmerman, B. J . (2002). Becoming a self-regulated learner: An overview. Theory into practice, 41(2), 64-70. https:// doi.org/ 10.1207/s15430421tip4102_2

Zimmerman, B. J ., \& Pons, M. M. (1986). Development of a structured interview for assessing student use of self-regulated learning strategies. American Educational Research J ournal, 23(4), 614- 628. https:// doi.org/ 10.3102/00028312023004614

\section{Athabasca} University

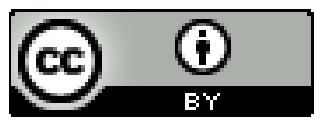

